$\begin{array}{cc}\text { ACADEMIA ROMÂNĂ } & \text { Rev. Roum. Chim., } \\ \text { Revue Roumaine de Chimie } & \text { 2020, 65(12), 1111-119 } \\ \text { http://web.icf.ro/rrch/ } & \text { DOI: } 10.33224 / \text { rrch.2020.65.12.06 }\end{array}$

\title{
NOVEL CHITOSAN-HYDROXYAPATITE MACROPOROUS COMPOSITES FOR BIOMEDICAL APPLICATIONS
}

\author{
Ioana A. DUCEAC and Fulga TANASA* \\ "Petru Poni” Institute of Macromolecular Chemistry, Grigore Ghica Voda Alley, Iasi 700487, Roumania; \\ e-mail: duceac.ioana@icmpp.ro; ftanasa@icmpp.ro
}

Composites made of natural and/or naturally-derived polymers intended for biomedical applications are expected to exhibit structures analogous to the natural ones, as well as valuable properties such as biologic compatibility and activity, and the ability to allow new, biologically recognizable interactions/signals with the host tissue. Under these circumstances, novel chitosanhydroxyapatite (Cs-HAp) macroporous composites were prepared through a simple procedure and subsequently characterized by the means of Fourier transformed infrared spectrometry (FTIR), scanning electron microscopy (SEM), X-ray diffractometry (XRD), and mechanical tests. Experimental data confirmed the materials have high porosity, originating in the structure of $\mathrm{Cs}$, and good mechanical properties, due to the presence of HAp, which enables them to be further employed in various biomedical applications, but only when low to moderate loads were used.

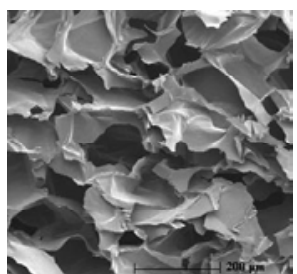

$\mathrm{a}-$ pure Cs

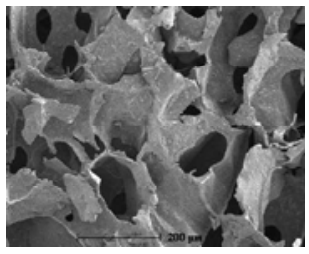

$\mathrm{c}-\mathrm{C} 40$

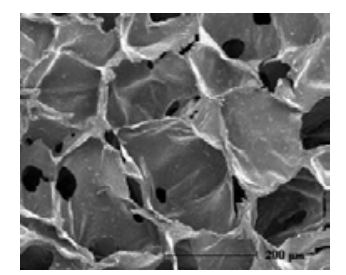

$\mathrm{b}-\mathrm{C} 20$

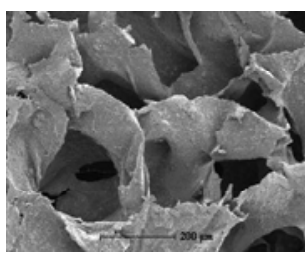

$\mathrm{d}-\mathrm{C} 50$

\section{INTRODUCTION}

Natural and/or naturally derived composite materials have become more and more important in biomedical applications for both soft and hard tissue engineering. Nowadays, there is an increasing demand of novel biologically active biomaterials, bioresorbable, and with tunable properties, aside their original biocompatibility, and able to mimic the functions of a specific tissue.

Chitosan (Cs), one of the most accessible naturally occurring polysaccharides, has proven to be an important component in the development of materials designed for tissue engineering and regenerative medicine due to its biocompatibility and capacity to decompose under physiological conditions (in the presence of lysozyme, especially under inflammatory conditions) without generating toxic compounds as by-products. It was extensively and intensively studied and, therefore, the literature is abundant on this topic. Nevertheless, chitosan was successfully employed as matrix for hydroxyapatite (HAp) filled composites intended for different biomedical applications. ${ }^{1-6}$ The main issue in the study of these materials is to find a balance between their flexibility and mechanical strength, given the structure and properties of Cs (a flexible biopolymer with low tensile strength) and HAp. These properties can be finely tuned by controlling the ratio between Cs and HAp, and wisely selecting the processing methods, in close correlation with their intended use (membranes, ${ }^{7,8}$ scaffolds, ${ }^{9-11}$ etc.).

\footnotetext{
* Corresponding author: ftanasa@icmpp.ro
} 
Hydroxyapatite is the main constitutive compound of the human bone (approx. 70\% wt.) and it was a natural choice for the preparation of biopolymers-based composites for bone restorative applications due to its high biologic activity and osteo-inducing characteristics. ${ }^{12,13}$ In order to improve the composites mechanical properties and biologic activity, HAp was employed into different matrices (made of either one single polymer or polymer blends), such as chitosan, ${ }^{14,15}$ poly (2, 2dimethyl trimethylene carbonate)s, ${ }^{16}$ collagen, ${ }^{17}$ and blends of chitosan with $\beta$-cyclodextrin, ${ }^{18}$ or synthetic and natural polymers (e.g., gelatin, ${ }^{19,20}$ nylon $6,{ }^{21}$ poly(vinyl alcohol), ${ }^{22}$ poly(lactic acid) ${ }^{23}$ collagen, ${ }^{24}$ poly ( $\varepsilon$-caprolactone $) .{ }^{25}$

Similar to other composite materials, the best results in terms of properties can be achieved when structural, morphological and compatibility criteria are simultaneously met by the selected components. Both Cs and HAp have very attractive properties, but high-performance Cs-HAp composites need to be thermodynamically stable, have a structure of interconnected pores, and display a highly homogeneous distribution of particles in bulk. Phenomena that can negatively influence the composite properties, such as secondary agglomeration, phase separation, and/or sedimentation, are of critical importance. These processes are known to occur during composites manufacturing for HAp particles of both micro- and nanometric size ${ }^{11}$ and their effects can be limited by selecting the processing method (freeze-drying, ${ }^{26}$ sonication ${ }^{27}$ ), using appropriate solvents (acetic acid, ${ }^{28,29}$ formic acid, ${ }^{1}$ malic $\left.\operatorname{acid}^{30}\right)$, modifying the surface of HAp particles, ${ }^{31}$ or even combining some of these methods.

This paper presents a series of novel Cs-HAp composites prepared by direct mechanical processing (mixing - kneading - ball milling) using commercially available medium size HAp powder (particle size 8.0-12.0 $\mu \mathrm{m}$ ). The effect of the increasing amount of HAp in the composite formulations on their mechanical properties was investigated, and the results were correlated with other experimental data.

\section{RESULTS AND DISCUSSION}

Cs-HAp composites were obtained through a simple procedure, namely direct mixing of HAp with Cs dissolved in small amounts of a dilute solution of acetic acid. The code and formulation (wt $\%)$ of composites samples are presented in Table 1, where the numbers in codes represent the content in HAp.

Table 1

Code and formulation of Cs-HAp composites

\begin{tabular}{c|c|c}
\hline \multirow{2}{*}{ Sample code } & $\begin{array}{c}\text { Composite } \\
\text { formulation } \\
\text { (wt\%) }\end{array}$ & \\
\cline { 2 - 3 } & HAp & Cs \\
\hline C5 & 5 & 95 \\
C10 & 10 & 90 \\
C20 & 20 & 80 \\
C40 & 40 & 60 \\
C50 & 50 & 50 \\
\hline
\end{tabular}

First structural investigations aimed at confirming the nature of bonds that were formed during the preparation of composites. For comparison, the FTIR spectra were recorded for both initial materials and composite samples. The characteristic absorption bands for Cs (Fig.1a) are as follows: at $3430 \mathrm{~cm}^{-1}$ is the signal characteristic to the stretching of the hydroxyl and amine groups; the peak at $2923 \mathrm{~cm}^{-1}$ is assigned to methylene moieties, as well as peaks at 1421, 1384 and $1322 \mathrm{~cm}^{-1}$; the band attributed to $\mathrm{C}=\mathrm{O}$ in amide I bond is at $1655 \mathrm{~cm}^{-1}$ - this a peak characteristic to the acetylated amine groups and in this case is a validation that Cs used for this study was partially deacetylated; the band recorded at $1587 \mathrm{~cm}^{-1}$ is assigned to the $\mathrm{NH}$ bending (amide II) in amine groups; absorption peak at $1322 \mathrm{~cm}^{-1}$ is correlated to the $\mathrm{C}=\mathrm{N}$ bond stretching, while the one at $1029 \mathrm{~cm}^{-1}$ is generated by the vibration of the C-O$\mathrm{C}$ glicozidic linkages. These data were confirmed by the literature. ${ }^{32,33}$

As for the HAp (Fig. 1b), the peaks characteristic to the phosphate groups are grouped in two nearby areas of the spectrum: 474, 572, $601 \mathrm{~cm}^{-1}$ attributed to the bending of phosphate bonds, and 972, 1040 and $1100 \mathrm{~cm}^{-1}$, respectively, owing to phosphate stretching. ${ }^{34,35}$ The peaks at 633 and $3570 \mathrm{~cm}^{-1}$ were generated by the vibration of -OH bonds, while the broad peaks at 3500 and $1660 \mathrm{~cm}^{-1}$ correspond to the adsorbed water. ${ }^{36}$ Two bands characteristic to carbonate moieties were recorded at 870 and $1430 \mathrm{~cm}^{-1}$. ${ }^{36}$

Regarding the composites, the recorded spectra are shown in Fig. 2. Due to the marked similarity of spectra of pure Cs and C5, in Fig. 2 are given only the spectra of samples C10-C50. 


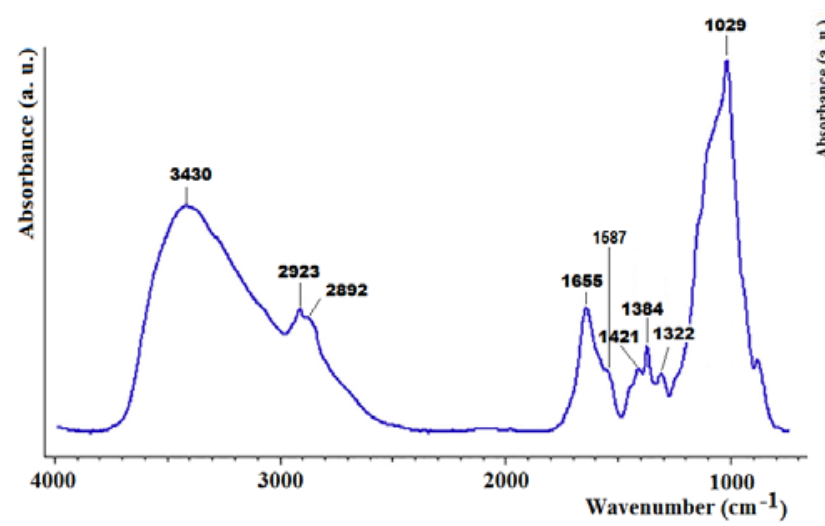

a

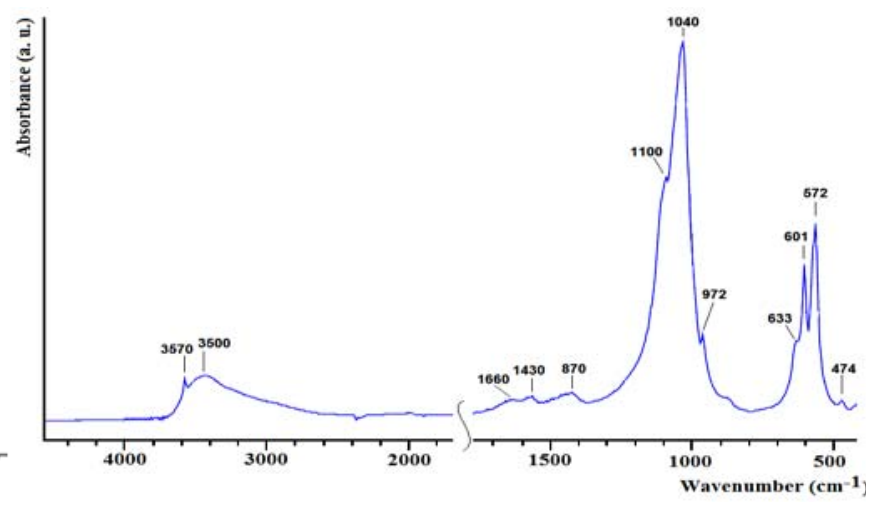

b

Fig. 1 -FTIR spectra of initial materials: $a$ - chitosan; $b$-hydroxyapatite.

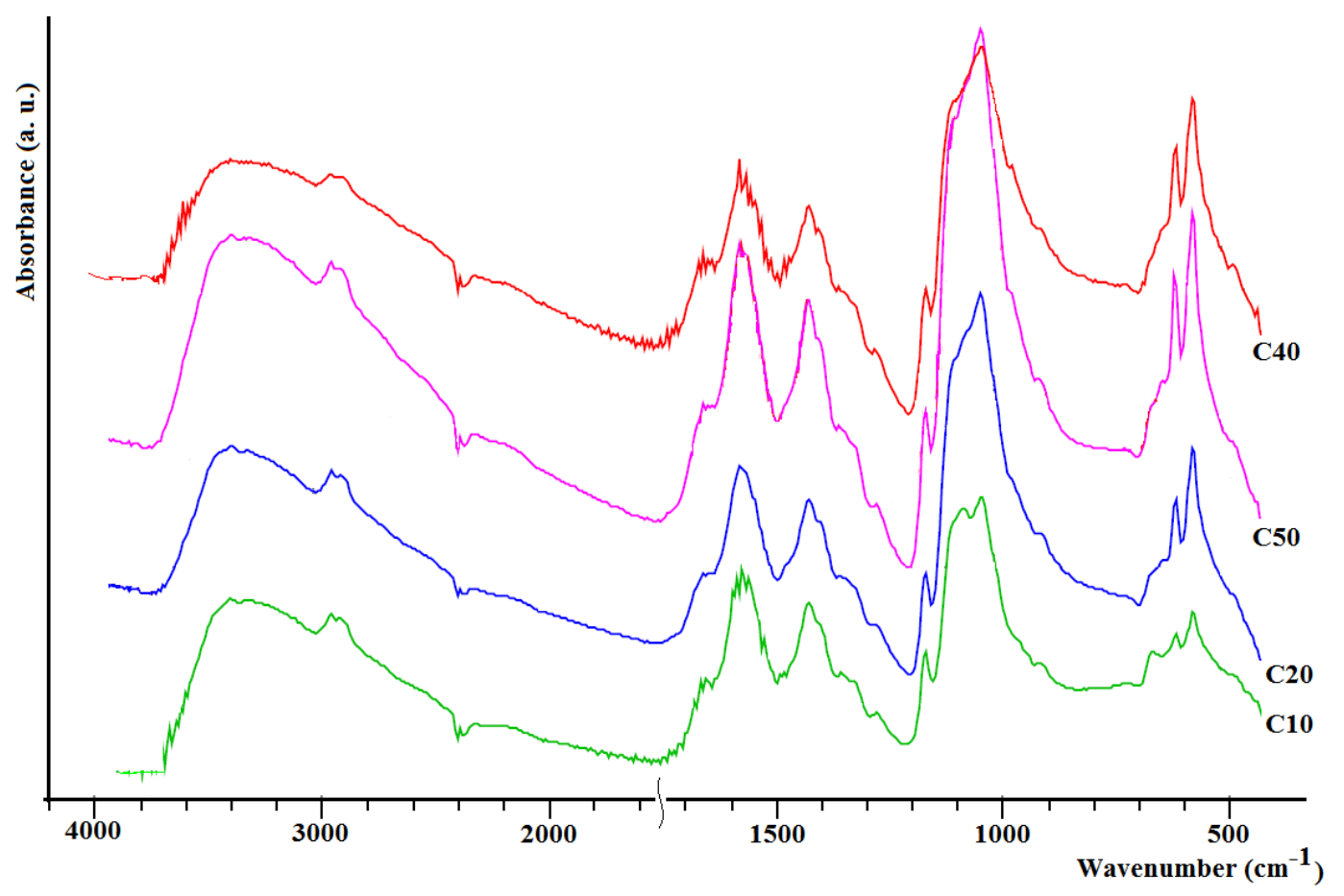

Fig. 2 - FTIR spectra of composite samples C10-C50.

Two main features are to be noticed from the very beginning. First, the peaks characteristic to pure Cs are modified very little or not at all, e.g., peaks at 1255 and $1058 \mathrm{~cm}^{-1}$ attributed to the primary amine groups at $\mathrm{C} 2$ carbon atom in the glucosamine ring, ${ }^{35,37}$ and peaks at 1565 and $1650 \mathrm{~cm}^{-1}$ corresponding to amide I groups and acetylated amine moieties, respectively). At the same time, peaks that are specific to HAp are also easy to identify: band characteristic to the phosphate bonds are slightly shifted to higher wavenumbers $(500-700$ and $\left.900-1050 \mathrm{~cm}^{-1}\right)$ indicating some weak interactions. The second relevant information is that the intensity of peaks characteristic to HAp is increasing along with the increasing amount of filler in the composite formulation, but there is no modification substantiating the formation of some chemical bonds.

There are recent studies that confirmed the formation of physical linkages only in composites made of raw CS and HAp, hence proving these composites belong to class I (where matrix and filler are connected only through physical interactions). ${ }^{38}$ The main type of interaction is the hydrogen bonding and ionic bridging, when available groups in $\mathrm{Cs} \mathrm{NH}_{2}$ and $-\mathrm{OH}$ ) are connecting with $\mathrm{OH}^{-}, \mathrm{Ca}^{2+}$ and $\mathrm{PO}_{4}{ }^{3-}$ moieties in HAp. Thermodynamic data indicated that the most stable configurations can be reached when $\mathrm{Ca}^{2+}$ and $\mathrm{PO}_{4}{ }^{3-}$ are linked by bridges with both $-\mathrm{NH}_{2}$ and $-\mathrm{OH}$ groups, as schematically illustrated in Fig. 3 , groups that can belong to one single unit (Fig. 3 a,d) or two adjoining units (Fig. 3 b,c) of Cs. 


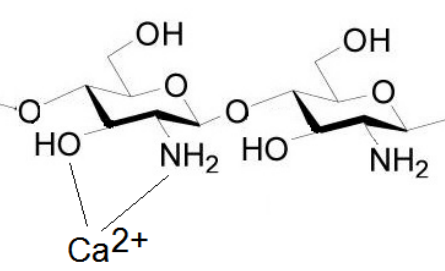

a

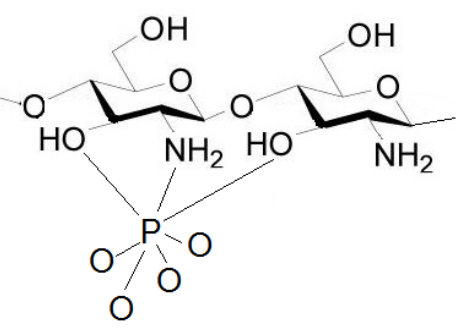

c

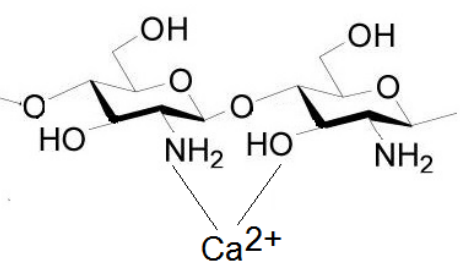

b

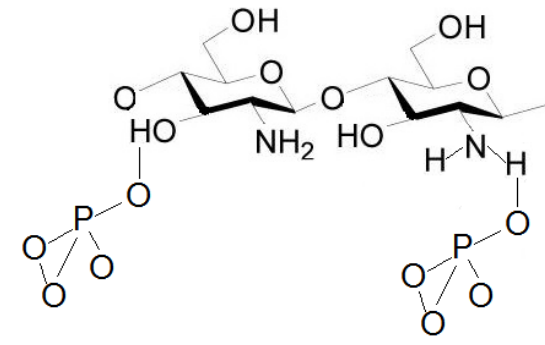

d

Fig. 3 - Possible interactions in class I composites made of raw Cs and HAp (as resulted from electronic and spectral data, and thermodynamic calculations).

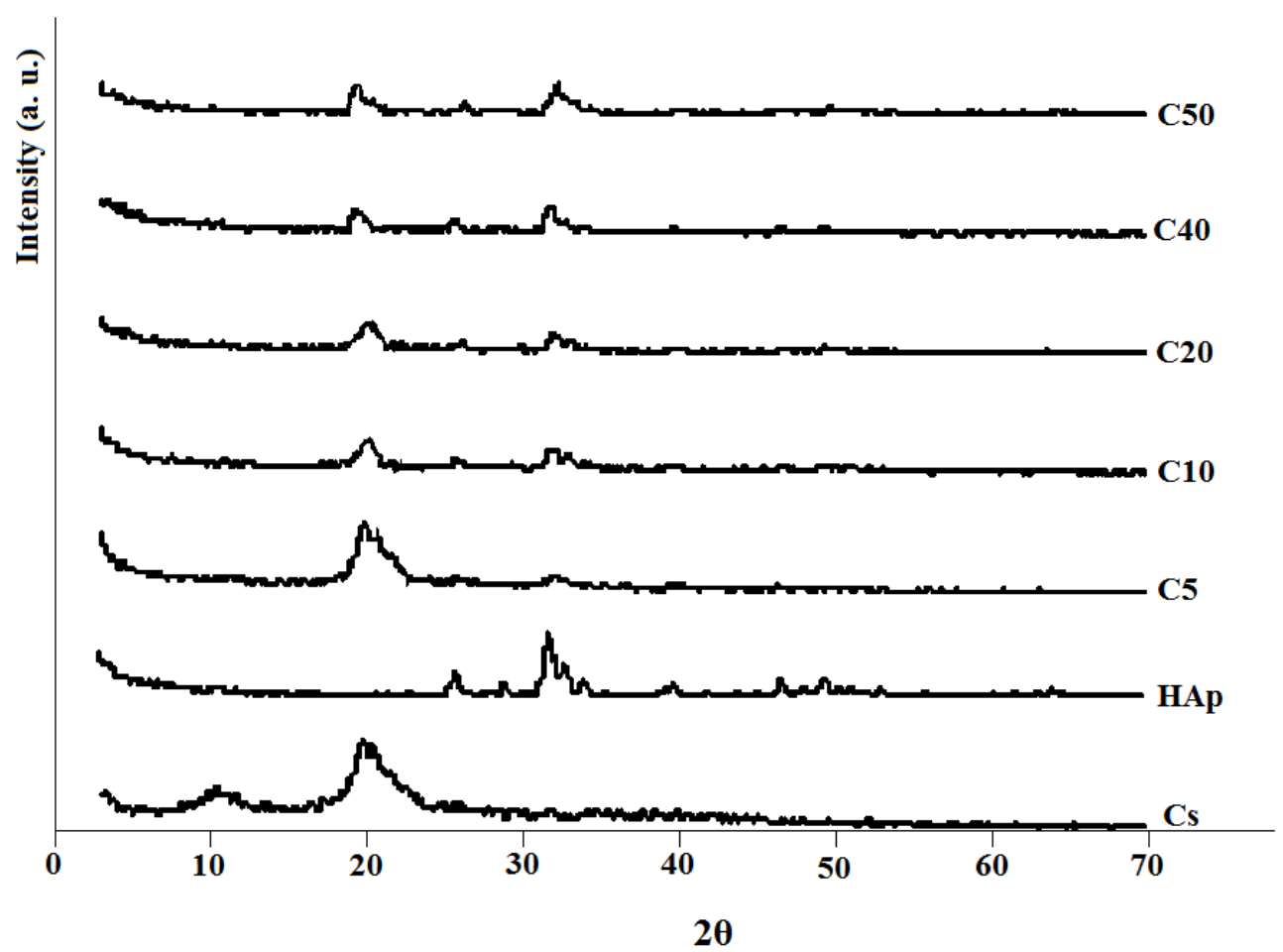

Fig. 4 - XRD patterns of all samples.

Even more, no charge transfer and no ionization occurred, but energy calculations indicated a decrease in the HOMO/LUMO gap energy caused by the Cs-HAp interactions. The calculated value of the dipole moment of Cs-HAp was higher than that of raw Cs, suggesting that the composites were more reactive than initial $\mathrm{Cs} .{ }^{38}$
The XRD study was performed on all samples and the recorded diffractograms are presented in Fig. 4.

XRD patterns of Cs and HAp showed specific diffraction maxima in different regions: at approx. $2 \theta=20$ - the strong signal is characteristic for Cs due to its crystallinity, ${ }^{39,40}$ while the characteristic 
signal of HAp is at approx. $2 \theta=32$. It is obvious that the intensity of signals corresponding to the composite samples is depending on the amount of HAp in their formulation: the higher the content in HAp, the higher is the intensity of diffraction maxima in that range. An interesting behavior was recorded for the Cs in composites, namely the shape and intensity of diffraction patterns were modified, suggesting that its crystallinity and types of crystallites were affected by the presence of HAp and the method of processing (ball milling). Some reports ${ }^{28,36}$ were also suggesting that HAp particles can cause the weakening of some intermolecular interactions which entailed certain molecular rearrangements in $\mathrm{Cs}$; hence, the crystallinity changes.

Electronic microscopy was employed for the morphology study of the Cs-HAp composite samples and the micrographs are showed in Fig. 5.

The main feature of these materials evidenced by SEM is their porosity originating in the structure of the Cs, as presented in Fig. 5a, where it is easy to notice the smooth surface of the interconnected pores, having dimensions in the range of $70-190 \mu \mathrm{m}$. For samples containing small amounts of HAp ( $5 \%$ and $10 \%$, respectively), morphological changes were not so evident (magnification 100x) as for the other samples (C20-50, Fig. 5 b, c, d). It is noteworthy that, aside preserving the porosity, the HAp particles were well embedded in Cs and their distribution was rather uniform. The pore surface rugosity was clearly increasing along with the content in HAp, while the distribution was maintained, and the pore dimensions slightly decreased. This feature might be considered an advantage of these new materials as it was substantiated that the presence of large interconnected pores improves the cellularity and the extracellular matrix content inside the scaffold, which may lead to larger structures obtained in shorter time intervals, ${ }^{41}$ although materials with pores smaller than $50 \mu \mathrm{m}$ have been indicated for biocompatible scaffolds with enhanced mechanical strength. ${ }^{42}$ At the same time, some flat pores (in pure Cs) changed their appearance to a rounder one, with stiffer walls, which was a definite indication of the improved mechanical strength of the samples (Fig. 5 c, d).

Mechanical characteristics of the Cs-HAp composite samples were evaluated in terms of elastic modulus and collapse stress, and acquired data are included in Table 2.

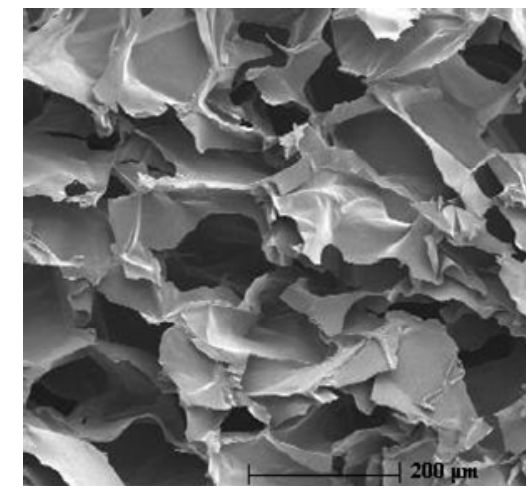

$\mathrm{a}-$ pure Cs

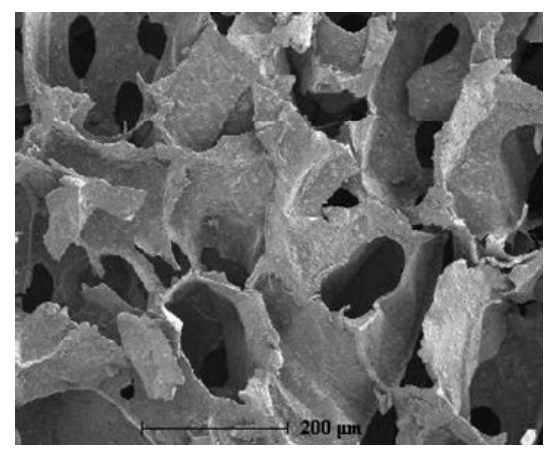

$\mathrm{c}-\mathrm{C} 40$

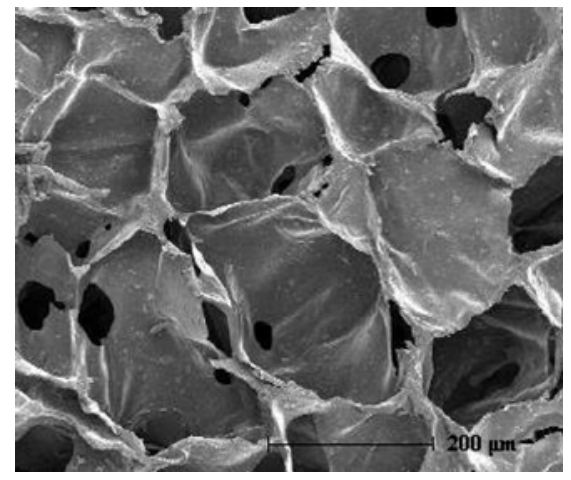

$\mathrm{b}-\mathrm{C} 20$

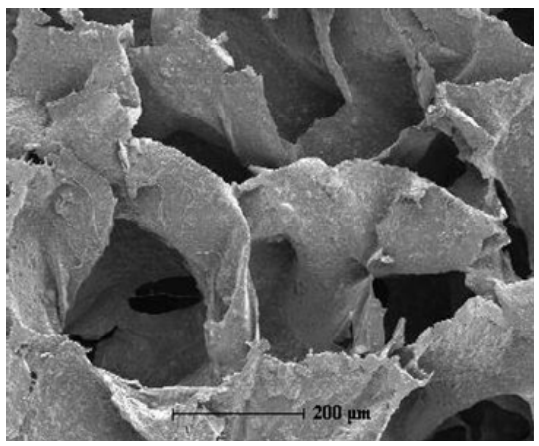

$\mathrm{d}-\mathrm{C} 50$

Fig. 5 - SEM micrographs of the selected samples: a - pure chitosan; b - C20 (20\% HAp); c - C40 (40\% HAp); d - C50 (50\% HAp). 
Table 2

Mechanical characteristics of the Cs-HAp composite samples

\begin{tabular}{c|c|c|c|c|c}
\hline $\begin{array}{c}\text { Sample } \\
\text { code }\end{array}$ & $\begin{array}{c}\text { HAp } \\
(\mathbf{w t} \%)\end{array}$ & $\begin{array}{c}\text { Density } \mathbf{a}, \\
\boldsymbol{\rho}\left(\mathbf{g} / \mathbf{c m}^{\mathbf{3}}\right)\end{array}$ & $\begin{array}{c}\text { Porosity } \\
\mathbf{( \% )}, \boldsymbol{\phi}\end{array}$ & $\begin{array}{c}\text { Elastic modulus, } \boldsymbol{E} \\
\mathbf{( M P a )}\end{array}$ & $\begin{array}{c}\text { Collapse stress, } \boldsymbol{\sigma} \\
\mathbf{( M P a )}\end{array}$ \\
\hline C5 & 5 & 0.067 & 93 & 5.98 & 0.13 \\
C10 & 10 & 0.072 & 93 & 6.73 & 0.14 \\
C20 & 20 & 0.081 & 94 & 8.86 & 0.16 \\
C40 & 40 & 0.086 & 95 & 8.90 & 0.18 \\
C50 & 50 & 0.091 & 94 & 9.44 & 0.20 \\
\hline
\end{tabular}

a - theoretical density of the composite material $(\rho)$ was calculated as a weighted average of the density of the two components of the composite per their weight ratio; ${ }^{43}$

$\mathrm{b}$ - porosity of the scaffolds was evaluated by gravimetry $;{ }^{44}$ the weight $(\mathrm{m})$ and dimensions (diameter $=\varnothing$ and thickness $\left.=\mathrm{h}\right)$ of samples were measured; porosity $(\phi)$ was calculated with the equation: $\phi(\%)=(\mathrm{m} / \rho \mathrm{V}) \times 100$

Experimental data obtained for the mechanical properties were correlated with the density and porosity of samples. It was observed that the density increased along with the increasing amount of HAp, as well as the values of the elastic modulus and collapse stress. At the same time, the porosity varied and this may be explained considering the gradual inclusion and distribution of HAp particles inside the Cs matrix: a reinforcing effect occurred, the pore walls became stiffer, and their increased roughness entailed a certain decrease in the pore dimensions, which is consistent with the information provided by SEM. These values of the mechanical properties are not close to those of the native bone, but they still recommend these new macroporous composites for cartilage reconstruction, although recent studies reported on macroporous HAp-filled composites used even for the bone restauration. ${ }^{45}$

Due to its biologic activity, HAp is able to trigger calcium phosphate deposition when in contact with body fluids due to the presence of the already existing crystallization nuclei onto the active surface of this ceramic material. This behavior may be used as a qualitative estimation of the biologic activity when new HAp-containing composite materials intended for biomedical applications are under study. In this context, an initial evaluation was performed in order to assess the composites stability and behavior under in vitro simulated physiological conditions: simulated body fluid (SBF) solution, $\mathrm{pH}=7.4$, incubation at $37^{\circ} \mathrm{C}$ and $\mathrm{p}\left(\mathrm{CO}_{2}\right)=0.005$ atm (5\%). This method was well established and the literature abounds in reports on this test as an indication of the biologic activity of a material, despite some recent pro and con debates substantiated by experimental data. ${ }^{46,47}$ The sample selected for this test was C50 as it contained the highest amount of HAp, so it was considered to enable the fastest response. For comparison, a control sample of Cs was also tested under similar conditions.

The first observation of our study was that the composite sample maintained its integrity in shape and structure, with no sign of fragmentation, after 7 days of incubation, which is an indication of its stability. Analyzing the SEM image of the composite sample C50 (Fig. 6, magnification $\mathrm{x} 4000$ ), it was easy to notice the surface alteration due to the formation of some cauliflower-like deposits which can be reasonably assumed to be amorphous calcium phosphate.

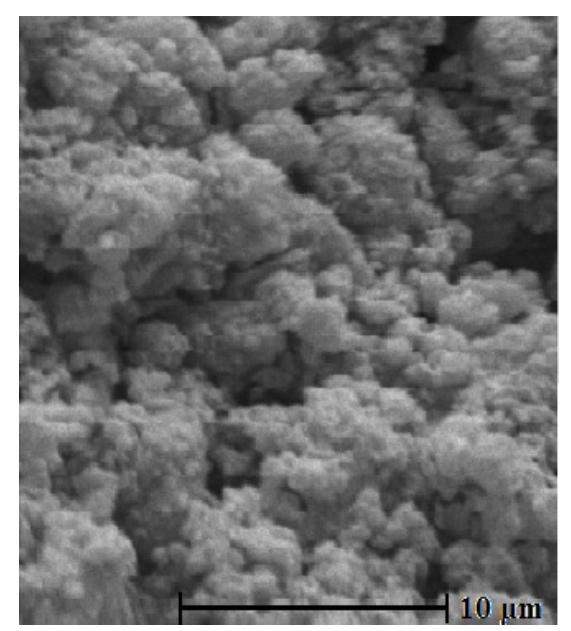

Fig. 6 - SEM image of sample C50 after immersion in SBF for 7 days.

It was not possible to identify this new layer of inorganic material by FTIR due to the overlapping signals of HAp. At the same time, a change in the surface roughness and pore dimension was also noticeable due to the deposition of the new layer of apatite.

The Cs sample showed no sign of deposition of inorganic material, confirming the key role of HAp in inducing this behavior to Cs-HAp composites in simulated biological environment. Still, an 
additional in-depth investigation is needed in order to provide further information regarding the nature and mechanism of formation of the detected deposit, reasonably assumed to be apatite, and to extend the study towards the analysis of the cellcomposite interaction, in order to assess the influence of these materials on the cell behavior (metabolic activity, cell adhesion), and reversely, the possible material transformation in the cell culture environment.

\section{EXPERIMENTAL}

\section{Materials}

Hydroxyapatite $\left(\mathrm{Ca}_{5}\left(\mathrm{PO}_{4}\right)_{3}(\mathrm{OH})\right.$ (Sigma-Aldrich, Germany; white powder, purity $99 \%$, ratio $\mathrm{Ca}: \mathrm{P}=1.67$, particle size 8.0 $12.0 \mu \mathrm{m}$, elastic modulus $117 \mathrm{GPa}$,) was oven-dried for $8 \mathrm{~h}$ at $180^{\circ} \mathrm{C}$, just before use. Low molecular weight chitosan (Sigma-Aldrich, Germany; average molecular weight $80 \mathrm{kDa}$ ) had a deacetylation degree of $75-85 \%$. All chemicals (SigmaAldrich, Germany) were used without further purification.

\section{Composites preparation}

In a typical procedure, the solution of chitosan was obtained by dissolving $1 \mathrm{~g}$ chitosan in $35 \mathrm{~mL}$ of $1 \mathrm{wt} \%$ acetic acid solution, under stirring (700 rpm), then it was left to rest for $24 \mathrm{~h}$, at room temperature. The HAp powder was added in preset amounts as to obtain composites with specific composition, namely increasing amounts of HAp (composites formulation and code are presented in Table 1), and mixed thoroughly first with a spatula, then kneaded using a mortar and pestle. After that, the mixture was transferred to a ball mill (Retsch MM 400 with an agate ball) for $6 \mathrm{~h}$, at room temperature. The resulting composite was removed, washed until the filtrate reached neutral $\mathrm{pH}$, and dried $\left(55^{\circ} \mathrm{C}\right.$, low vacuum, $24 \mathrm{~h})$, then processed into discs $(\mathrm{L} / \mathrm{D}=1)$ under uniaxial pressure $(30 \mathrm{MPa})$.

\section{Characterization}

The FTIR spectra were recorded on a Bruker Vertex 70 spectrometer using the $\mathrm{KBr}$ pellet method.

The morphology studies (SEM) were performed using a VEGA II SBH scanning electron microscope manufactured by TESCAN (Brno, Czech Republic). Samples were cryogenically fractured by immersion in liquid nitrogen for 30-50 min. Shortly after fracturing, the rupture surfaces were coated with a thin layer of silver (of about $50 \mathrm{~nm}$ ) and then examined under the electron beam (magnification 100x). An operating voltage of $30 \mathrm{kV}$ was used. The pore size was studied using ImageJ software.

The X-ray diffractograms (WAXD) were recorded on a Diffractometer D8 ADVANCE (Bruker AXS, Germany), using the $\mathrm{Cu}-\mathrm{K} \alpha$ radiation $(\lambda=0.1541 \mathrm{~nm})$, a parallel beam with Gobel mirror and a Dynamic Scintillation detector (parameters: current $40 \mathrm{kV}$ and $30 \mathrm{~mA}$; count time $2 \mathrm{~s} / \mathrm{step}$, step size 0.02 degree/step). All the diffractograms were investigated in the range $10-70^{\circ}$ ( $2 \theta$ degrees), at room temperature.

The mechanical tests were performed on a Shimadzu AGS-J deformation device (at room temperature and a rate of deformation of $10 \mathrm{~mm} / \mathrm{min}$, a load cell able to measure forces up to $1 \mathrm{kN}$ ). For each point, five samples were tested, and the average value was taken.

The in vitro behavior of Cs-HAp composites was studied using simulated body fluid (SBF), prepared according to the protocol described by Kobuko and Takadama. ${ }^{46}$ Pre-weighted samples were incubated in test tubes, at $37^{\circ} \mathrm{C}$ and $\mathrm{p}\left(\mathrm{CO}_{2}\right)=5 \%$, for 7 days, using SBF $1.5 \mathrm{~g} / \mathrm{L}$ as recommended in literature reports. ${ }^{26,48,49}$ At the end of the incubation time, the materials were washed with deionized water, dried at $50^{\circ} \mathrm{C}$ and assessed gravimetrically to confirm the weight gain.

\section{CONCLUSIONS}

It is well known that mechanical properties of native bones are higher than those of composites made of HAp-reinforced natural polymers. It also has been proven that composite scaffolds having increased porosity, with either small or large interconnected pores, can successfully promote the mechanical fixation, at higher rates, of implants within the host tissue by providing a recognizable template for the tissue regeneration. ${ }^{4,50}$ Macroporous scaffolds allow larger amounts of extracellular matrix, thus favoring the cell proliferation, mineral deposition, structural organization, and vascularization. Hence, the constant demand for such composites able to be used in tissue engineering with good results.

The new Cs-HAp macroporous composites were prepared by direct mechanical processing (mixing - kneading - ball milling) using commercially available medium size HAp powder (particle size $8.0-12.0 \mu \mathrm{m}$ ). The experimental data obtained during the materials characterization lead to the following conclusions.

Their morphology and the presence of the large interconnected pores were confirmed, as well as their structural stability after testing under simulated physiological conditions (SBF).

A satisfactory level of mechanical performance has been reached due to the presence of HAp particles with reinforcing effect. Given the particle size of HAp, the amount of filler in the composite was maintained at low to moderate in order to partially preserve the material elasticity (provided by Cs), while increasing the mechanical strength (afforded by HAp), as it is known that brittle materials were obtained at higher filler content, when the continuous phase of the Cs matrix does no longer exist and a rigid skeleton of HAp was formed.

The biologic activity was evaluated in vitro and found to be promising, although further investigation is required. 
Based on the results presented herein, these materials can be recommended as scaffold for cartilage regeneration, or even for cancellous bone reconstruction. Even more, since the filler is not very expensive (commercially available medium size HAp particles) in comparison with nanoparticulate fillers, and the amount used in materials preparation is low to moderate, it is possible to modulate the relationship between production costs and level of performance so that various formulations of macroporous Cs-HAp composites could be manufactured in accordance with distinct applications.

Acknowledgements. The authors gratefully acknowledge the contribution of Dr. Irina Pelin ("Petru Poni" Institute of Macromolecular Chemistry, Iasi, Roumania) and Dr. Malgorzata Basko (Centre of Molecular and Macromolecular Studies, Łódź, Poland) to this study.

\section{REFERENCES}

1. M. A. Nazeer, E. Yilgör and I. Yilgör, Carbohydrate Polymers, 2017, 175, 38-46.

2. G. Fernandez de Grado, L. Keller, Y. Idoux-Gillet, Q. Wagner, A. M. Musset, N. Benkirane-Jessel, F. Bornert and D. Offner, J. Tissue Eng., 2018, 9, 2041731418776819.

3. H. E. Jazayeri, M. D. Fahmy, M. Razavi, B. E. Stein, A. Nowman, R. M. Masri and L. Tayebi, J. Prosthodontics, 2016, 25, 510-517.

4. L. Pighinelli and M. Kucharska, Carbohydrate Polymers, 2013, 93, 256-262.

5. C. Liu, Y. Liu, S. Li, Y. Sun, Y. Li, C. Jiang and Q. Hu, J. Biomater. Tissue Eng., 2017, 7, 28-34.

6. M. Dash, F. Chiellini, R. M. Ottenbrite and E. Chiellini, Progress in Polym. Sci., 2011, 36, 981-1014.

7. C. Shi, C. Lv, L. Wu and X. Hou, J. Hazardous Mater., 2017, 338, 241-249.

8. J. Mota, N. Yu, S. G. Caridade, G. M. Luz, M. E. Gomes, R. L. Reis, J. A. Jansen, X. F. Walboomers and J. F. Mano, Acta Biomaterialia, 2012, 8, 4173-4180.

9. I. G. Beşkardeş, T. T. Demirtaş, M.D. Durukan and M. Gümüşderelioğlu, J. Tissue Eng. and Regenerative Med., 2015, 9, 1233-1246.

10. L. Kong, Y. Gao, W. Cao, Y. Gong, N. Zhao and X. Zhang, Journal of Biomedical Materials Research Part A: An Official Journal of The Society for Biomaterials, The Japanese Society for Biomaterials, and The Australian Society for Biomaterials and the Korean Society for Biomaterials, 2005, 75, 275-282.

11. D. Tsiourvas, A. Sapalidis and T. Papadopoulos, Mater. Today Comm., 2016, 7, 59-66.

12. A. Rogina, L. Pribolšan, A. Hanžek, L. Gómez-Estrada, G.G. Ferrer, I. Marijanović, M. Ivanković and H. Ivanković, Polymer, 2016, 98, 172-181.

13. Y. Lei, Z. L. Xu, Q. F. Ke, W. J. Yin, Y. X. Chen, C. Q.hang and Y. P. Guo, Mater. Sci. \& Eng. C-Mater. for Biol. Appl., 2017, 72, 134-142.

14. M. Ito, Y. Hidaka, M. Nakajima, H. Yagasaki and A. H. Kafrawy, Journal of Biomedical Materials Research: An Official Journal of The Society for Biomaterials, The
Japanese Society for Biomaterials, and The Australian Society for Biomaterials, 1999, 45, 204-208.

15. A. Zima, Spectrochim. Acta Part A: Molec. and Biomolec. Spectroscopy, 2018, 193, 175-184.

16. M. Socka, A. Michalski, I. M. Pelin, A. Pawlak, F. Tanasa, T. Biela and M. Basko, Polymer, 2020, 186, 122078.

17. M. N. Ştefănut, A. Căta, D. Roşu, M. Milea and I. M. C. Ienaşcu, Rev. Roum. Chim., 2017, 62, 481-487.

18. M. Shakir, R. Jolly, M. S. Khan, A. Rauf and S. Kazmi, Int. J. Biol.l Macromolec., 2016, 93, 276-289.

19. K. R. Mohamed, H. H. Beherei and Z. M. El-Rashidy, J. Advanced Research, 2014, 5, 201-208.

20. J. Zhang, J. Nie, Q. Zhang, Y. Li, Z. Wang and Q. Hu, J. Biomater. Sci., Polymer Edition, 2014, 25, 61-74.

21. A. Abdal-hay, A. S. Hamdy, Y. Morsi, K. A. Khalil and J. H. Lim, Mater. Lett., 2014, 137, 378-381.

22. D. Yang, Y. Jin, G. Ma, X. Chen, F. Lu and J. Nie, J. Appl. Polym. Sci., 2008, 110, 3328-3335.

23. X. Cai, H. Tong, X. Shen, W. Chen, J. Yan and J. Hu, Acta Biomaterialia, 2009, 5, 2693-2703.

24. Y. Wang, L. Zhang, M. Hu, H. Liu, W. Wen, H. Xiao and Y. Niu, Journal of Biomedical Materials Research Part A: An Official Journal of The Society for Biomaterials, The Japanese Society for Biomaterials, and The Australian Society for Biomaterials and the Korean Society for Biomaterials, 2008, 86, 244-252.

25. F. M. Ghorbani, B. Kaffashi, P. Shokrollahi, E. Seyedjafari and A. Ardeshirylajimi, Carbohydrate Polym., 2015, 118, 133-142.

26. L. Gritsch, M. Maqbool, V. Mourino, F. E. Ciraldo, M. Cresswell, P. R. Jackson, C. Lovell and A. R. Boccaccini, J. Mater. Chem. B, 2019, 7, 6109-6124.

27. F. Batmanghelich and M. Ghorbani, Ceramics Int., 2013, 39, 5393-5402.

28. O. Yildirim, "Preparation and characterization of chitosan/calcium phosphate based composite biomaterials", Master of Science Dissertation, İzmir Institute of Technology, İzmir, Turkey, 2004.

29. A. Yoshida, T. Miyazaki, E. Ishida and M. Ashizuka, Mater. Transactions, 2004, 45, 994-998.

30. K. A. Nelson, "Processing and Characterization of Chitosan and Hydroxyapatite filled Polymer Composites", MSc Thesis, Stony Brook University, New York, USA, 2009.

31. B. H. Atak, B. Buyuk, M. Huysal, S. Isik, M. Senel, W. Metzger and G. Cetin, Carbohydrate Polym., 2017, 164, 200-213.

32. C. E. Tanase, I. M. Popa and L. Verestiuc, J. Biomed. Mater. Res. B App.l Biomater., 2012, 100, 700-708.

33. F. D. Cojocaru, V. Balan, M. I. Popa, A. Lobiuc, A. Antoniac, I. V. Antoniac and L. Verestiuc, Int. J. Biol. Macromolec., 2019, 125, 612-620.

34. F. Heidari, M. E. Bahrololoom, D. Vashaee and L. Tayebi, Ceram. Int., 2015, 41, 3094-3100.

35. F. Chen, Z. C. Wang and C. J Lin, Materials Letters, 2002, 57, 858-861.

36. I. Yamaguchi, K. Tokuchi, H. Fukuzaki, Y. Koyama, K. Takakuda, J. Monma and H. Tanaka, J. Biomed. Mater. Research, 2001, 55, 20-27.

37. Q. Yuan, J. Shah, S. R. D. K. Hein and R. D. K. Misra, Acta Biomaterialia, 2010, 6, 1140-1148.

38. E. S. M. El-Sayed, A. Omar, M. Ibrahim and W. I. Abdel-Fattah, J. Comput. and Theor. Nanosci., 2009, 6, $1663-1669$. 
39. K. Ogawa, T. Yui and M. Miya, Biosci., Biotechn. Biochem., 1992, 56, 858-862.

40. S. Jana, S.J. Florczyk, M. Leung and M. Zhang, J. Mater. Chem., 2012, 22, 6291-6299.

41. D. J. Griffon, M. Reza Sedighi, D. V. Schaeffer, J. A. Eurell and A. L. Johnson, Acta Biomaterialia, 2006, 2, 313-320.

42. M. Kon and A. C.de Visser, Plast. Reconstr. Surg., 1981, 67, 288-294.

43. L. Gritsch, M. Maqbool, V. Mourino, F. E. Ciraldo, M. Cresswell, P. R. Jackson, C. Lovell and A. R. Boccaccini, J. Mater. Chem. B, 2019, 7, 6109-6124.

44. E. Boccardi, A. Philippart, V. Melli, L. Altomare, L. De Nardo, G. Novajra, C. Vitale-Brovarone, T. Fey and A. R. Boccaccini, Ann. Biomed. Eng., 2016, 44, 1881-1893.

45. P. Kazimierczak, K. Palka and A. Przekora, Biomolecules, 2019, 9, 434; doi:10.3390/biom9090434
46. T. Kokubo and H. Takadama, Biomaterials, 2006, 27, 2907-2915.

47. M. Bohner and J. Lemaitre, Biomaterials, 2009, 30, 2175-2179.

48. A. L. B. Macon, T. B. Kim, E. M. Valliant, K. Goetschius, R. K. Brow, D. E. Day, A. Hoppe, A. R. Boccaccini, I. Y. Kim, C. Ohtsuki, T. Kokubo, A. Osaka, M. Vallet-Reg1, D. Arcos, L. Fraile, A. J. Salinas, A. V. Teixeira, Y. Vueva, R. M. Almeida, M. Miola, C. Vitale-Brovarone, E. Verne, W. Holand and J. R. Jones, J. Mater. Sci.: Mater. Med., 2015, 26, 1-10.

49. F. Ciraldo, L. Liverani, L. Gritsch, W. Goldmann and A. Boccaccini, Materials, 2018, 11, 692; doi:10.3390/ ma11050692

50. A. E. Porter, T. Buckland, K. Hing, M. S. Best and W. Bonfield, J. Biomed. Mater. Res., 2006, 78A, 25-33. 
